\title{
Correspondence
}

We welcome letters to the Editor concerning articles which have recently been published. Such letters will be subject to the usual stages of selection and editing; where appropriate the authors of the original article will be offered the opportunity to reply.

Letters should normally be under 300 words in length, double-spaced throughout, signed by all authors and fully referenced. The edited version will be returned for approval before publication.

\section{The radial and posterior interosseous nerves}

Sir,

We read with interest the article in July 2001 issue by Shergill et $\mathrm{al}^{1}$ entitled 'The radial and posterior interosseous nerve: results of 260 repairs.'

We have performed repair of the radial nerve in 11 patients using a different technique. ${ }^{2}$ Our patients had repair in the spiral groove 12 months after injury. They were followed up clinically and electrophysiologically over a period of four years with good results.

Anatomical studies have consistently shown two branches of the radial nerve to the medial head of triceps arising proximal to the spiral grove. The larger of these two branches was used for nerve grafting with good results in defects in which mobilisation and end-to-end anastomosis were not possible.

We agree that the outcome of successful repair of the radial nerve is better than musculotendinous transfer. This new technique of nerve repair should be considered in patients in whom end-to-end anastomosis is not possible. It would be akin to anatomical continuity of the root value of the nerve. If there is no clinical and electrophysiological improvement, then ultimately a musculotendinous transfer can be carried out.

S. ORAKWE, FRCS

R. GORE, FRCS Ed

University Hospital Lewisham

London, UK.

1. Shergill G, Bonney G, Munshi P, Birch R. The radial and posterior interosseous nerves: results of 260 cases. J Bone Joint Surg [Br] 2001;83-B:646-9.

2. Gore RV. A new method of nerve repair: repair of a lesion of the radial nerve with a branch to the triceps muscle. $B r J$ Surg 1978;65:352-3.

\section{Author's reply:}

Sir,

I much appreciate the interest of Mr Gore and Mr Orakwe in our article, and in particular their reference to the excellent technique of repair by nerve transfer of severe lesions of radial nerves. I was very impressed by the work when I first read the original article.

Our own experience with nerve transfers in lesions which are otherwise irreparable has been mixed. ${ }^{1}$ I think that it is fair to say

(C)2001 British Editorial Society of Bone and Joint Surgery 0301-620X/02/313277 $\$ 2.00$

J Bone Joint Surg [Br] 2002;84-B:462-4. that the use of intercostal nerves to reinnervate the wrist extensors has been disappointing. The technique described by $\mathrm{Mr}$ Gore and $\mathrm{Mr}$ Orakwe is undoubtedly a valuable one.

R. BIRCH, MChir, FRCS

Royal National Orthopaedic Hospital

Stanmore, UK.

1. Birch R, Bonney G, Wynn Parry CB. Iatro-pathic injury. In: Surgical disorders of the peripheral nerves. 1st edition. London: Churchll Livingstone, 1998:293-333.

\section{The inferior capsular shift operation for instability of the shoulder: long-term results in 34 shoulders}

\section{Sir,}

I read with interest the article in the March 1999 issue entitled 'The inferior capsular shift operation for instability of the shoulder: long-term results in 34 shoulders' by Hamada et al. ${ }^{1}$ In 11 of 25 shoulders, the authors found some posterolateral defects in the humeral head with irregular surfaces. Nine had a posterior approach or combined posterior and anterior approaches, and two had an anterior approach. These defects were not related to any history of anterior dislocation, were seen secondarily after the operation at a mean of 0.91 years and presented an increasing size and depth in five shoulders. Lateral radiographs showed an irregularity which did not correspond to a site of impaction or bony erosion related to an aggressive synovitis. MRI showed a low signal and the authors concluded that this unusual aspect could be partial postoperative osteonecrosis. Gerber, Schneeberger and Vinh ${ }^{2}$ have described the role of one branch of the anterior circumflex artery, the arteria arcuata, which is the main intraosseous vessel seen in the humeral head, and a recent study ${ }^{3}$ has demonstrated that the arterial blood of the subchondral bone of the humeral head is supplied by the posterior circumflex artery in 29 of 32 anatomical specimens. The hypothesis of a posterior osteonecrosis with a secondary local collapse needs confirmation.

F. DUPARC, MD, PhD

Hôpital Charles Nicolle

Rouen, France.

1. Hamada K, Fukuda H, Nakajima T, Yamada N. The inferior capsular shift operation for instability of the shoulder: long-term results in 34 shoulders. J Bone Joint Surg [Br] 1999;81-B:218-25.

2. Gerber $\mathbf{C}$, Schneeberger AG, Vinh TS. The arterial vascularization of the humeral head: an anatomical study. J Bone Joint Surg [Am] 1990;72-A:1486-94.

3. Duparc F, Muller JM, Freger P. Arterial blood supply of the proximal humeral epiphysis. Surg Radiol Anat 2001;23:185-90.

\section{Author's reply:}

Sir

We thank Dr Duparc for his interest in our article.

We performed the operation according to Neer's original procedure. We freshened the bone at the sulcus at the posterior neck of the humerus with a chisel and/or a rongeur to facilitate healing of the ligament and capsule to bone in the posterior approach. This could damage the entry of the posterior circumflex 
artery into the humeral head and cause necrosis of the posterior part which is supplied mainly by this vessel.

His findings which showed that the arterial blood supply to the subchondral bone of the humeral head was by the posterior circumflex artery in 29 of 32 anatomical specimens may explain the cause of posterolateral necrosis of the humeral head in our series. Since we observed such a high rate of posterolateral necrosis (9/14 shoulders), we have now modified our technique. We retract the posterior deltoid muscle superiorly and develop the interval between infraspinatus and teres minor. In order to protect the entry of the posterior circumflex artery, we incise the capsule near its glenoid attachment, and create superior and inferior capsular flaps instead of incising the capsule at the anatomical neck and freshening the sulcus. Since adopting this modification, we have not observed posterolateral necrosis of the humeral head.

We agree that it is clinically important to preserve the supply from the posterior circumflex artery to the humeral head in order to prevent osteonecrosis after a posterior approach to the shoulder.

K. HAMADA, MD

Tokai University School of Medicine

Kanagawa, Japan.

\section{Treatment for displaced intracapsular fracture of the proximal femur}

\section{Sir,}

I read with interest the article by Davison et al in the March 2001 issue entitled 'Treatment for displaced intracapsular fracture of the proximal femur: a prospective, randomised trial in patients aged 65 to 79 years', and would welcome comment on two points. First, in those cases internally fixed, the manner of the failure seems quite different from that of other studies in which nonunion and avascular necrosis are the predominant cause. Was cut-out of the lag screw associated with these or was it a feature of the fixation device used? If it was the latter, better results may be expected with other fixation devices.

Secondly, the reader is not told the results of the salvage procedures and as $30 \%$ of the internal fixation group underwent these this is important information in deciding which of the interventions to adopt.

G. BANNISTER, MD, MCh (Orth), FRCS, FRCS Ed Orth

Southmead Hospital

Bristol, UK.

1. Davison JNS, Calder SJ, Anderson GH, Ward G, Jagger C, et al. Treatment for displaced intracapsular fracture of the proximal femur: a prospective, randomised trial in patients aged 65 to 79 years. $J$ Bone Joint Surg [Br] 2001;83-B:206-12.

\section{Author's reply:}

\section{Sir,}

We thank Mr Bannister for his interest in our paper. With regard to methods of failure, 14 internal fixations $(15 \%)$ failed as a result of the lag screw cutting out of the femoral head, all within 120 days of fixation. None of these could be reasonably attributed to nonunion or avascular necrosis. The remaining failures were later secondary to avascular necrosis. The sliding screw plate is a commonly-used device for fixation of intracapsular fractures, and a recent meta-analysis by Parker has shown that it achieves similar results to other methods. We think therefore that the rate of failure which we present is that achieved if a good method of fixation is used.

With regard to salvage arthroplasty, in most cases this was by total hip replacement. The rate of attendance at review clinics in this group of patients was poor, and therefore it is difficult to draw definitive conclusions as to the results of salvage arthroplasty. We hope that this will result in some further work in the future.

J. N. S. DAVISON, FRCS

Leicester Royal Infirmary

Leicester, UK.

1. Parker MJ, Blundell C. Choice of implant for internal fixation of femoral neck fractures: a meta-analysis of 25 randomised trials including 4925 patients. Acta Orthop Scand 1998; 69:138-43.

\section{A comparison of polyethylene wear in hips with cobalt-chrome or zirconia heads}

Sir

I read with interest the article in the July 2001 issue by YoungHoo Kim et al entitled 'A comparison of polyethylene wear in hips with cobalt-chrome or zirconia heads'.

There were a number of variables in this study, but in particular it was noted that all 70 patients with the cobalt-chrome heads had Profile femoral components which were uncemented. The 70 patients who had the zirconia heads had Elite/Elite plus femoral components which were cemented.

In 1994 Hernandez et $\mathrm{al}^{2}$ showed increased rates of wear of polyethylene in uncemented compared with cemented femoral components when examining wear rates with a single acetabular component.

In the light of this, I think that it is very difficult to draw any conclusions about the comparative rates of wear of zirconia and cobalt-chrome heads since the differing femoral prostheses used in this study may have had an effect on outcome.

\section{R. HARGROVE, FRCS I \\ Surrey \\ UK.}

1. Kim Y-H, Kim JS, Cho SH. A comparison of polyethylene wear in hips with cobalt-chrome or zirconia heads: a prospective, randomised study. J Bone Joint Surg [Br] 2001;83-B:742-50.

2. Hernandez JR, Keating EM, Faris PM, Meding JB, Ritter MA. Polyethylene wear rates in uncemented acetabular components. J Bone Joint Surg [Br] 1994;76-B:263-6.

\section{Authors' reply:}

Sir,

I appreciate Mr Hargrove's interest in our article, and I thank him for pointing out a relevant article ${ }^{1}$ which gives useful information regarding the wear rates of polyethylene in uncemented and cemented femoral components. There are several studies which report on cementless acetabular fixation either with a cemented (a hybrid hip) or cementless stem. That of Callaghan et $\mathrm{al}^{2}$ suggests that the wear rate of a cementless femoral component can be equal to or perhaps better than that of a cemented femoral component. Those of Hernandez et $\mathrm{al}^{1}$ and Nashed, Backer and Gustilo ${ }^{3}$ suggest that polyethylene wear may be increased with cementless fixation. These results should be interpreted with caution because of the association with titanium-alloy femoral heads. Because of the decreased resistance to abrasion of titanium alloy, the performance of a bearing with this material would be affected to a greater degree.

Cemented and cementless fixation of the femoral stem in our study are important variables for comparing the wear rate of the polyethylene liner. Unlike other reports, our study was carried out in patients who had bilateral simultaneous total hip replacements in order to eliminate other variables such as age, gender, comorb- 
idities, diagnosis and activity level. In both groups in our study, no hip had aseptic loosening and all implants were well fixed. Therefore we believe that our study was relatively well controlled and allowed determination of the rate of wear of the polyethylene.

YOUNG-HOO KIM, MD

The Joint Replacement Centre of Korea

Seoul, Korea.

1. Hernandez JR, Keating EM, Faris PM, Meding JB, Ritter MA. Polyethylene wear in uncemented acetabular components. J Bone Joint Surg [Br] 1994;76-B:263-6.

2. Callaghan JJ, Pedersen DR, Olejniczak JP, Goetz DD, Johnston RC. Radiographic measurement of wear in 5 cohorts of patients observed for 5 to 22 years. Clin Orthop 1995;317:14-8.

3. Nashed RS, Backer DA, Gustilo RB. Are cementless acetabular components the cause of excess wear and wear in total hip arthroplasty? Clin Orthop 1995;317:19-28.

\section{Current concepts of respiratory insufficiency syndromes after fracture}

Sir,

The review entitled 'Current concepts of respiratory insufficiency syndromes after fracture' by Robinson ${ }^{1}$ in the August 2001 issue presented a detailed overview of fat embolism syndrome (FES), adult respiratory distress syndrome (ARDS) and pneumonia relating to trauma patients with fractures. There are two forms of posttraumatic ARDS, both of which result from dysfunction of the patient's inflammatory response to major trauma. ${ }^{2}$ Early posttraumatic ARDS is a result of the activation of this response. When injuries are particularly severe, this may be a 'one-hit event,' with pulmonary injury occurring as "an inevitable consequence" of the patient's injuries. Alternatively, the injuries may be sufficient to prime the inflammatory response, but activation depends on a 'second hit,' which may be persisting occult tissue hypoperfusion or even surgical trauma. ${ }^{3,4}$ Late ARDS occurs after three to five days and is associated with the development of infection. It is unclear whether infection associated with late ARDS is a cause of or a symptom of this delayed inflammatory dysfunction. Studies examining ARDS related to musculoskeletal trauma rarely consider the differences in the pathology.

Early stabilisation of fractures is an integral part of the care of the patient with major trauma. ${ }^{5}$ The beneficial effects are hard to explain scientifically. Studies tend to show an increase in the inflammatory response, which would be expected to be detrimental. ${ }^{6-8}$ This is not often the case. Waydhas et $\mathrm{al}^{9}$ have shown, however, that delayed surgery can be a 'second hit' which precipitates ARDS/MOF in patients with raised C-reactive protein and serum elastase complex and thrombocytopenia.

The 'unstable patients' not included in the analysis of early versus delayed fracture treatment are surely the group of greatest interest. ${ }^{4,10,11}$ By understanding exactly what the benefits of early surgery are in biological terms, it may be possible to refine the care of the most unstable patients. By using fracture surgery as an adjunct to resuscitation and ultimately being able to intervene medically to restore the dysfunctional inflammatory response to normality, improvements in survival could be anticipated even in patients who have the worst prognosis.

I. PALLISTER, FRCS

University Hospital Wales

Cardiff, UK.
1. Robinson CM. Current concepts of respiratory insufficiency syndromes after fractures. J Bone Joint Surg [Br] 2001;83-B:781-91.

2. Moore FA, Moore EE. Evolving concepts in the pathogenesis of postinjury multiple organ failure. Surg Clin North Am 1995;75:257-77.

3. Blow O, Magliore L, Claridge JA, Butler K, Young JS. The golden hour and the silver day: detection and correction of occult hypoperfusion within 24 hours improves outcome from major trauma. J Trauma 1999;47:964-9.

4. Crowl AC, Young JS, Kahler DM, et al. Occult hypoperfusion is associated with increased morbidity in patients undergoing early femur fracture fixation. $J$ Trauma 2000;48:260-7.

5. Bone LB, McNamara K, Shine B, Border J. Mortality in multiple trauma patients with fractures. J Trauma 1994;37:262-4.

6. Nast-Kolb D, Waydhas C, Jochum M, et al. Is there a favourable time for the management of femoral shaft fractures in polytrauma? Chirurg 1990;61:259-65.

7. Giannoudis PV, Smith RM, Bellamy MC, et al. Stimulation of the inflammatory system by reamed and unreamed nailing of femoral fractures: an analysis of the second hit. J Bone Joint Surg $[\mathrm{Br}]$ 1999;81-B:356-61.

8. Gago LA, Moore EE, Patrick DA, et al. Secretory phospholipase A2 cleavage of intravasated bone marrow primes human neutrophils. $J$ Trauma 1998;44:660-4.

9. Waydhas C, Nast-Kolb D, Trupka A, et al. Post-traumatic inflammatory response, secondary operations and late multiple organ failure. J Trauma 1996;40:624-30.

10. van der Made WJ, Smit EJ, van Luyt PA, van Vugt AB. Intramedullary femoral osteosynthesis: an additional cause of ARDS in multiply injured patients? Injury 1996;27:391-3.

11. Boulanger BR, Stephen D, Brenneman FD. Thoracic trauma and early intramedullary nailing of femur fractures: we are doing harm? $J$ Trauma 1997;43:24-8.

\section{Author's reply:}

Sir,

I thank Mr Pallister for his comments on my article. He correctly points out that the aetiology of ARDS is usually different dependent on the timing of its onset. In the early stages, an overwhelming inflammatory response is usually implicated, whereas in the late form, sepsis is usually considered to be the major cause. I am grateful for his clarification of the two current theories of the pathological processes ('one-hit' and 'two-hit' models), which I have also outlined briefly in my article.

I agree with Mr Pallister that 'unstable' patients are of considerable interest, but it is not possible within the existing literature to examine them systematically. They remain a poorly defined group and, as I emphasised in my article, patients with fractures of the long bones and true 'physiological instability' are rare. Nowotarski et al $^{1}$ reporting from one of the largest tertiary referral centres in the USA, found that only $5 \%$ of their patients with fractures of the long bones of a lower limb were in this group. Further work to clarify the basic biological and pathological processes in these individuals may help to enable discrete therapeutic interventions to be made in the future, as an adjunct to surgical intervention.

\section{M. ROBINSON}

Royal Infirmary of Edinburgh

Edinburgh, UK.

1. Nowotarski PJ, Turen CH, Brumback RJ, Scarboro JM. Conversion of external fixation to intramedullary nailing for fractures of the shaft of the femur in multiply injured patients. J Bone Joint Surg [Am] 2000;82-A:781-8. 